\title{
Dermatoglyphics in Leukemia
}

\author{
W. Wertelecki ${ }^{[21]}$, G. C. Plato, J. F. Fraumeni, and J. D. Niswander \\ Epidemiology Branch, National Cancer Institute and Medical Genetics Section, Departments of Pathology and Pediatrics, Medical Uni- \\ versity of South Carolina, Charleston, South Carolina; Gerontology Research Center, National Institute of Child Health and Human \\ Development, Baltimore City Hospitals, Baltimore, Maryland; Epidemiology Branch, National Cancer Institute; and National \\ Institute of Dental Research, National Institutes of Health, Bethesda, Maryland, USA
}

\section{Extract}

The study of dermatoglyphic features of 76 Caucasian patients with acute lymphocytic leukemia revealed that male patients had higher frequency of digital whorls $(33 \%)$ than their brothers $(26.7 \%)$ or fathers $(27.8 \%)$. Patients with leukemia and their sibs had more Sydney palmar flexion creases $(41.3 \%$ and $35.4 \%$ ) than their parents $(10.9 \%)$ or two control groups $(20.4 \%$ and $10.5 \%)$.

\section{Speculation}

The association of acute lymphocytic leukemia to increased frequency of digital whorl patterns and Sydney palmar flexion creases can now be tested prospectively. Confirmation of an association between leukemia and these dermatoglyphic features would indicate a relationship between prenatal characteristics and leukemogenesis.

\section{Introduction}

Dermatoglyphics are metrical features of development reflecting the influence of environmental and hereditary factors operating during the first trimester of gestation. Although the documentation of an association between leukemia and dermatoglyphic features strongly suggest the presence of prenatal factors relating to the risk or etiology of leukemia, recent studies exploring the subject have left the issue unsettled [ $\mathrm{l}-3$, $5-7,10-14,16-18]$.

\section{Materials and Methods}

We studied 4.3 male and 33 female unrelated Caucasian patients suffering from acute lymphocytic leukemia, referred to the Leukemia Service of the National Cancer Institute from all areas of the country. All but eight patients were under 15 years of age. A developmental history and physical examination was performed for each patient. Patients with major structural defects or mental retardation were excluded from the study group. As control subjects, we studied 200 first degree relatives of the patients, of whom 39 were brothers, 48 sisters, 45 fathers, and 68 mothers. In addition, two control groups were used for comparisons of frequencies of abnormal palmar flexion creases. The first control group (control $A$ ) is composed of 135 male and 84 female normal Caucasian individuals from the Charleston area, $21 \%$ of whom were less than 10 years of age, $24 \%$ between 10 and 19 years, and $55 \%$ between 20 and 30 years of age. The second control group (control $B$ ) is composed of 203 male and 204 female 7-year-old normal Caucasian children from the Boston area who were a part of the Perinatal Research Survey [9].

The finger and palm prints were obtained by the standard ink method. Interpretation of each print was done using standard classifications. Modal types of the $\mathrm{C}$ lines were classified using the method described by Plato [8].

Palm flexion creases were classified into normal, simian, or Sydney creases (Fig. 1). Simian and Sydney creases were subclassified into complete or aberrant 

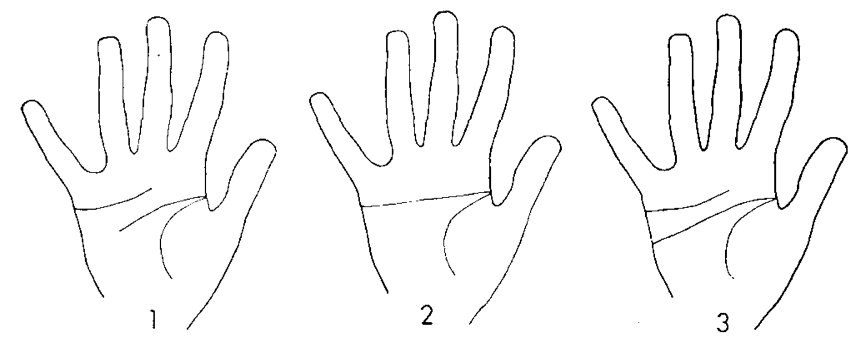

Fig. 1. Palmar flexion creases. 1: Normal; 2: simian crease; 3: Sychey crease.

types. A simian flexion crease was defined as complete if the proximal and distal palmar creases fused into the classic single transverse line; all other forms of simian line, which did not meet the "complete" criterion, were considered as aberrant. A Sydney line was defined as complete when the proximal transverse palmar flexion crease reached the ulnar margin of the palm. A Sydney line was defined as aberrant when the line failed to reach the ulnar margin by only a few millimeters.

In view of the acknowledged difference of some dermatolyphic traits between males and females, group comparisons of palmar and digital dermatoglyphic features were made between the patients, their sibs and parents of like-sex. Male patients were compared with brothers and fathers and female patients to sisters and mothers.

We used the fingertip pattern intensity index (PII) in several comparisons. The PII is calculated by assigning the quantity 2 to each whorl, 1 to each loop, and 0 to each arch. The sum of the numbers assigned to the pattern of the 10 fingers of an individual is his pattern intensity index. The midparental PII is the average (midvalue) between the paternal and maternal PII values. In sibships in which a patient had a sib of the same sex, comparisons of PII were made within the family unit. We had 30 such families, 20 with a male and 10 with a female propositus. The PII of male and female patients were compared with the PII of their respective sibs of the same sex and their midparental PII. The digital ridge counts of the same 30 patients were calculated by the method of Holt [4] and compared with those of their like-sex sibs.

Group comparisons of the frequency of abnormal palmar flexion creases were made between the patients, sibs, parents, and normal control subjects. Comparisons were made among these groups by sex and by combination of data from both sexes. Comparisons were statistically evaluated using chi-square contingency tables or Student's $t$ test whenever appropriate.

\section{Results}

Group comparisons of dermatoglyphic patterns of patients, their sibs, and parents of like sex revealed differences in digital patterns and modal types of the palmar C line. Digital whorl patterns were more frequent in male patients with leukemia than the group of brothers $(P<0.0 \mathrm{I})$. The group of sisters had more digital arches than either female patients with leukemia or mothers $(P<0.01)$ (Table I). These differences were significant using either $4 \times 2$ or $2 \times 2$ contingency tables (four digital pattern categories or presence or absence of a given pattern). Such results, however, cannot be accepted uncritically, as the chi-square test assumes independence of patterns for each digit of an individual. Preferable is the utilization of a single value reflecting the patterns of all 10 digits, the pattern intensity index (PII). Although the PII tended to be higher in patients with leukemia, the differences in group comparisons were not significant (Table I). Although our results from group comparisons suggest a real difference in finger patterns of patients with leukemia, a larger sample is needed to show this conclusively, even though this suggestion finds further support from paired comparisons of patients with leuke-

Table I. Frequency of digital patterns and pattern intensity indices of children with leukemia and their relatives

\begin{tabular}{|c|c|c|c|c|c|c|}
\hline \multirow{2}{*}{ Subjects } & \multirow{2}{*}{ No. } & \multicolumn{4}{|c|}{ Digital patterns, $\%$} & \multirow{2}{*}{$\begin{array}{c}\text { Pattern } \\
\text { intensity } \\
\text { index }\end{array}$} \\
\hline & & Whorls & $\begin{array}{l}\text { Ulnar } \\
\text { loops }\end{array}$ & $\begin{array}{l}\text { Radial } \\
\text { loops }\end{array}$ & Arches & \\
\hline \multicolumn{7}{|l|}{ Males } \\
\hline Patients & 43 & 33.0 & 59.8 & 5.1 & 2.1 & 13.10 \\
\hline Brothers & 39 & 26.7 & 59.5 & 6.2 & 7.7 & 11.90 \\
\hline Fathers & 45 & 27.8 & 63.1 & 4.4 & 4.7 & 12.31 \\
\hline \multicolumn{7}{|l|}{ Females } \\
\hline Patients & 33 & 24.8 & 66.7 & 4.5 & 3.9 & 12.09 \\
\hline Sisters & 48 & 24.8 & 58.9 & 4.6 & 11.7 & 11.31 \\
\hline Mothers & 68 & 25.0 & 66.6 & 4.0 & 4.4 & 12.06 \\
\hline
\end{tabular}

Table II. Frequency of the modal types of the $\mathrm{C}$ line of patients and their relatives

\begin{tabular}{|c|c|c|c|c|c|}
\hline \multirow{2}{*}{ Subjects } & \multirow{2}{*}{ No. } & \multicolumn{4}{|c|}{ Modal types of the $\mathrm{C}$ line, $\%$} \\
\hline & & Radial & Ulnar & Proximal & Absent \\
\hline \multicolumn{6}{|l|}{ Males } \\
\hline Patients & 42 & 35.7 & 47.6 & 10.7 & 6.0 \\
\hline Brothers & 38 & 35.5 & 46.1 & 14.5 & 3.9 \\
\hline Fathers & 43 & 31.4 & 37.2 & 22.1 & 9.3 \\
\hline \multicolumn{6}{|l|}{ Females } \\
\hline Patients & 33 & 25.8 & 40.9 & 24.2 & 9.1 \\
\hline Sisters & 44 & 31.8 & 42.0 & 11.4 & 14.8 \\
\hline Mothers & 67 & 34.3 & 50.3 & 11.9 & 4.0 \\
\hline
\end{tabular}



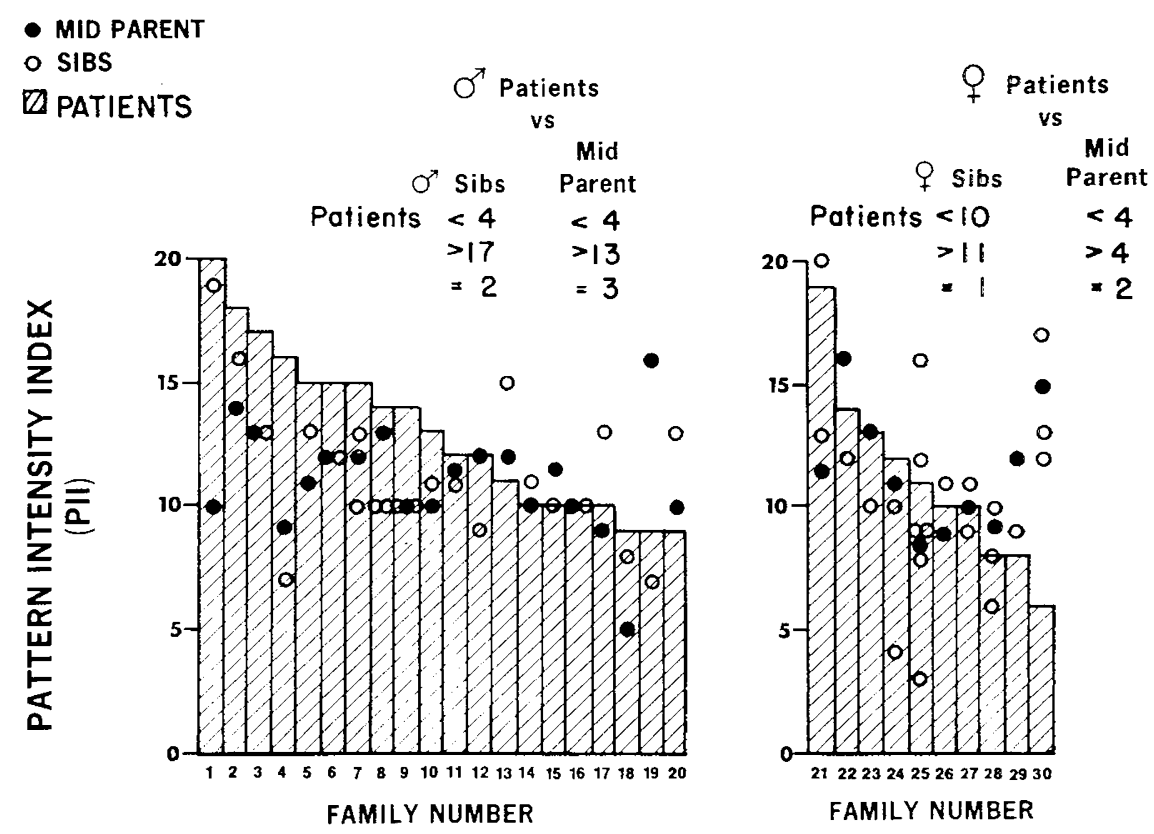

Fig. 2. Comparison of the pattern intensity indices (PII) of patients to the PII of their own sibs and their midparental PII.

Table III. Frequency of individuals with abnormal palmar creases ${ }^{1}$

\begin{tabular}{|c|c|c|c|c|c|c|c|c|c|c|}
\hline \multirow{3}{*}{ Crease } & \multicolumn{5}{|c|}{ Sydney, $\%$} & \multicolumn{5}{|c|}{ Simian, $\%$} \\
\hline & \multirow[b]{2}{*}{$\underset{(75)}{\text { Patients }}$} & \multirow[b]{2}{*}{$\begin{array}{l}\text { Sibs } \\
(82)\end{array}$} & \multirow[b]{2}{*}{$\begin{array}{c}\text { Parents } \\
(110)\end{array}$} & \multicolumn{2}{|c|}{ Control subjects } & \multirow[b]{2}{*}{$\underset{(75)}{\text { Patients }}$} & \multirow[b]{2}{*}{$\begin{array}{l}\text { Sibs } \\
(82)\end{array}$} & \multirow[b]{2}{*}{$\begin{array}{c}\text { Parents } \\
(110)\end{array}$} & \multicolumn{2}{|c|}{ Control subjects } \\
\hline & & & & $\underset{(219)}{\mathrm{A}}$ & $\underset{(407)}{B}$ & & & & $\underset{(219)}{\mathrm{A}}$ & $\underset{(407)}{\mathrm{B}}$ \\
\hline \multicolumn{11}{|l|}{ Unilateral } \\
\hline Complete & 10.7 & 19.5 & 2.7 & 1.8 & 6.1 & 8.0 & 0.0 & 3.7 & 2.3 & 3.7 \\
\hline Aberrant & 18.7 & 8.5 & 6.4 & 5.5 & 10.6 & 6.7 & 7.3 & 9.1 & 2.3 & 2.2 \\
\hline \multicolumn{11}{|l|}{ Bilateral } \\
\hline Complete & 5.3 & 0.0 & 0.9 & 0.0 & 1.0 & 1.3 & 1.2 & 0.0 & 0.4 & 1.7 \\
\hline Complete-aberrant & 4.0 & 4.9 & 0.9 & 0.9 & 1.5 & 1.3 & 2.4 & 0.9 & 0.0 & 1.0 \\
\hline Aberrant & 2.7 & 2.4 & 0.0 & 2.3 & 1.2 & 0.0 & 3.7 & 0.9 & 0.4 & 0.0 \\
\hline Total bilateral ${ }^{2}$ & 12.0 & 7.3 & 1.8 & 3.2 & 3.7 & 2.6 & 7.3 & 1.8 & 0.8 & 2.7 \\
\hline Unilateral and bilateral combined ${ }^{2}$ & 41.3 & 35.4 & 10.9 & 10.5 & 20.4 & 17.3 & 14.6 & 13.6 & 5.4 & 8.6 \\
\hline At least one complete crease ${ }^{2}$ & 16.0 & 19.5 & 3.6 & 1.8 & 7.1 & 9.3 & 1.2 & 3.7 & 2.7 & 5.4 \\
\hline
\end{tabular}

${ }^{1}$ Number of individuals examined is shown in parentheses.

${ }^{2}$ Categories tested.

mia with their own sibs of like sex discussed subsequently.

Analysis of palmar dermatoglyphic features revealed that proximal or absent modal types of the $\mathrm{C}$ line were more common in female patients with leukemia than in the mothers $(P<0.05)$ and that absent modal types were more common in sisters than in mothers $(P<$ 0.02) (Table II).

No differences were observed in the modal types of the $\mathrm{D}$ line, main line indices, interdigital, hypothenar, and thenar configurational areas, accessory triradii, or the width of atd angles.

Comparisons of each patient to his sibs of the same sex were possible in 30 families; 20 with a male and 10 with a female propositus. Paired comparisons for pattern intensity indices (PII) were made for these sibships and the results are presented in Figure 2. The intrafamily comparisons of PII values (Fig. 2) show 
Table IV. Significant differences in the frequency of abnormal palmar creases among leukemia patients, their first degree relatives, and control $B^{2}$

\begin{tabular}{|c|c|}
\hline Abnormal palmar crease & $p$ \\
\hline \multicolumn{2}{|l|}{ Sydney } \\
\hline \multicolumn{2}{|l|}{ Patients $v s$ parents } \\
\hline Total unilateral & $<0.005$ \\
\hline Total bilateral & $<0.025^{2}$ \\
\hline Unilateral and bilateral combined & $<0.005$ \\
\hline At least one complete crease & $<0.005$ \\
\hline At least one aberrant crease & $<0.005$ \\
\hline \multicolumn{2}{|l|}{ Patients vs control $B$} \\
\hline Total unilateral & $<0.01$ \\
\hline Total bilateral & $<0.01^{2}$ \\
\hline Unilateral and bilateral combined & $<0.005$ \\
\hline$\Lambda t$ least one complete crease & $<0.005$ \\
\hline At least one aberrant crease & $<0.01$ \\
\hline \multicolumn{2}{|l|}{ Sibs vs parents } \\
\hline Total unilateral & $<0.005$ \\
\hline Unilateral and bilateral combined & $<0.005$ \\
\hline At least one complete crease & $<0.005$ \\
\hline \multicolumn{2}{|l|}{ Sibs vs control $B$} \\
\hline Total unilateral & $<0.025$ \\
\hline Unilateral and bilateral combined & $<0.005$ \\
\hline At least one complete crease & $<0.005$ \\
\hline \multicolumn{2}{|l|}{ Parents vs control $B$} \\
\hline Total unilateral & $<0.05$ \\
\hline Unilateral and bilateral combined & $<0.025$ \\
\hline \multicolumn{2}{|l|}{ Simian } \\
\hline \multicolumn{2}{|l|}{ Patients vs control $B$} \\
\hline Total unilateral & $<0.025^{2}$ \\
\hline Unilateral and bilateral combined & $<0.025$ \\
\hline \multicolumn{2}{|l|}{ Sibs vs control $B$} \\
\hline$\Lambda t$ least one aberrant crease & $<0.005^{2}$ \\
\hline \multicolumn{2}{|l|}{ Parents vs control $B$} \\
\hline Total unilateral & $<0.05$ \\
\hline At least one aberrant crease & $<0.005$ \\
\hline
\end{tabular}

${ }_{1}$ Control $B$ is presented because abnormal palmar flexion creases were more frequent in control $B$ than in control $A$. Control $B$ was significantly different from control $A$ in the frequency of individuals with unilateral Sydney creases $(P<0.005)$, unilateral and bilateral Sydney creases $(P<0.005)$, at least one complete Sydney crease $(P<0.005)$, and at least one complete simian crease $(P<0.05)$.

${ }^{2}$ Chi-square with Yates' correction.

that male patients with leukemia have a distinctive trend to have higher PII values than their brothers. When the PII of male patients with leukemia are compared with their own midparental PII, patients with leukemia show the same trend toward higher PII values while their normal sibs do not. The female patients with leukemia showed no such differences when their PII was compared with their own sisters' or their midparental PII, but comparisons were possible in only 10 sibships. The mean total digital ridge counts for the male patients and sibs were $133.5 \pm 8.2$ and $120.4 \pm 8.8$, respectively, and those for the female patients and sibs were $116.7 \pm 12.7$ and $112.7 \pm 14.7$. Although the patients had a tendency to have higher total digital ridge counts, the differences between patients and their sibs in paired or group comparisons is nevertheless a nonsignificant one.

Table III shows the frequency of Sydney and simian palmar flexion creases in the patients with leukemia, their relatives, and two normal control groups. The data were evaluated and compared separately for each relationship and sex as in the previous tables. However, since no significant differences were found between males and females in any of the comparisons, the data were pooled and Table III shows the frequencies of abnormal palmar flexion creases for both sexes combined. Inasmuch as some of the entries in Table III were small numbers, only the totals were used for statistical comparisons. Every one of these categories was compared for every relationship by using $2 \times 2$ contingency chi-square tables. The comparisons which revealed statistically significant differences are listed in Table IV. The results listed in Table IV show the following. (1) Patients with leukemia have more Sydney creases than parents or control subjects. (2) Sibs of patients with leukemia also have more Sydney creases than parents or control subjects. (3) There are no differences between patients with leukemia and their sibs. (4) The parents and normal control subjects are very similar to each other.

The frequencies of palmar flexion simian creases were, for the most part, similar in all comparison groups.

\section{Discussion}

Dermatoglyphic features are measurable characters of development which achieve differentiation during early gestation and remain immutable throughout the lifetime of each individual. If dermatoglyphic studies document that children with leukemia have distinctive dermatoglyphic features, this would indicate the existence of a correlation between developmental fetal characteristics, operating during the first trimester of gestation, and leukemogenesis. 
Table V. Summary of 10 dermatoglyphic studies on leukemia ${ }^{1}$

\begin{tabular}{|c|c|c|c|c|c|c|c|c|c|c|c|}
\hline \multirow{4}{*}{$\begin{array}{l}\text { Type of } \\
\text { leukemia }\end{array}$} & \multirow{4}{*}{$\begin{array}{c}\text { No. of } \\
\text { cases }\end{array}$} & \multirow{4}{*}{ Sex } & \multicolumn{8}{|c|}{ Dermatoglyphic patterns } & \multirow{4}{*}{ Series } \\
\hline & & & \multicolumn{6}{|c|}{ Fingertip patterns, $\%^{2}$ (patients vs control subjects) } & \multicolumn{2}{|c|}{ Palmar flexion creases } & \\
\hline & & & \multicolumn{2}{|c|}{ Whorls } & \multicolumn{2}{|c|}{ Radial loops } & \multicolumn{2}{|c|}{ Arches } & \multirow[b]{2}{*}{ Sydney crease } & \multirow[b]{2}{*}{ Simian Crease } & \\
\hline & & & Cases & $\begin{array}{l}\text { Control } \\
\text { subjects }\end{array}$ & Cases & $\begin{array}{l}\text { Control } \\
\text { subjects }\end{array}$ & Cases & $\begin{array}{l}\text { Control } \\
\text { subjects }\end{array}$ & & & \\
\hline $\begin{array}{l}\text { Acute } \\
\text { CML }\end{array}$ & $\begin{array}{r}24 \\
1\end{array}$ & $M \& F$ & 25.2 & 22.8 & 7.6 & 5.7 & 6.8 & 3.8 & Increased & No difference & Menser et al. [5] \\
\hline ALL & 13 & $\mathrm{M}$ & 46.2 & 27.2 & 6.2 & 4.9 & 3.8 & 5.3 & & & \\
\hline$A M L$ & 15 & $\mathrm{M}$ & 41.3 & 27.2 & 1.3 & 4.9 & 6.7 & 5.3 & & & \\
\hline Acute & 32 & $M$ & 41.9 & 27.2 & 3.4 & 4.9 & 5.0 & 5.3 & & & \\
\hline CIML & 14 & $\mathrm{M}$ & 34.5 & 27.2 & 6.5 & 4.9 & 2.9 & 5.3 & No difference & No difference & Verbov $[14]$ \\
\hline CLL & 22 & M & 26.0 & 27.2 & 8.7 & 4.9 & 0.5 & 5.3 & & & \\
\hline Chronic & 36 & $\mathrm{M}$ & 29.3 & 27.2 & 7.8 & 4.9 & 1.4 & 5.3 & & & \\
\hline ALL & 3 & $F$ & 13.3 & 26.0 & 10.0 & 4.5 & 0.0 & 4.3 & & & \\
\hline AML & 9 & $\mathrm{~F}$ & 34.4 & 26.0 & 2.2 & 4.5 & 5.6 & 4.3 & & & \\
\hline Acute & 17 & $F$ & 28.8 & 26.0 & 4.7 & 4.5 & 6.5 & 4.3 & & & \\
\hline CML & 13 & $\mathrm{~F}$ & 28.8 & 26.0 & 1.6 & 4.5 & 8.0 & 4.3 & & & \\
\hline CLL & 12 & $\mathrm{~F}$ & 26.7 & 26.0 & 4.2 & 4.5 & 8.3 & 4.3 & & & \\
\hline Chronic & 25 & $\mathrm{~F}$ & 27.7 & 26.0 & 2.9 & 4.5 & 8.2 & 4.3 & & & \\
\hline ALL & 28 & $\mathrm{M}$ & 37.5 & 28.6 & 4.6 & 5.7 & 2.5 & 3.6 & Increased & No difference & Wertelecki et al. [16] \\
\hline ALL & 26 & $\mathrm{~F}$ & 25.8 & 25.8 & 3.8 & 3.1 & 3.8 & 6.1 & & & \\
\hline \multirow[t]{2}{*}{ ALL } & 43 & M & 33.0 & $27.8^{3}$ & 5.1 & $4 \cdot 4^{3}$ & 2.1 & $4.7^{3}$ & Increased & No difference & Present Study \\
\hline & & & & $26.7^{4}$ & & $6.2^{4}$ & & $7.7^{4}$ & & & \\
\hline \multirow[t]{2}{*}{ ALL } & 33 & $\mathrm{~F}$ & 24.8 & $25.0^{5}$ & 4.5 & $4.0^{5}$ & 3.9 & $4.4^{5}$ & & & \\
\hline & & & & $24.8^{6}$ & & $4.6^{6}$ & & 11.76 & & & \\
\hline Acute & 20 & $M \& F$ & 27.6 & 22.5 & Not & ated & 9.0 & 6.5 & Increased & No difference & Zahalkova st al. [18] \\
\hline \multirow[t]{2}{*}{ Acutc } & 65 & M & 30.0 & 26.8 & 6.0 & 5.7 & 6.5 & 4.4 & Increased & No difference & Menser et al. [6] \\
\hline & 50 & $F$ & 29.4 & 24.7 & 5.0 & 4.8 & 3.4 & 6.0 & Increased & Increased & \\
\hline Acute & 50 & $M \& F$ & 28.3 & 26.9 & 4.6 & 4.6 & 7.0 & 5.4 & No difference & No difference & Berka et al. [2] \\
\hline $\mathrm{AML}$ & 4 & & & $28.8^{5}$ & & $3.2^{5}$ & & $10.0^{5}$ & & & \\
\hline ALL & 16 & $M$ & \multicolumn{2}{|c|}{ Not stated } & \multicolumn{2}{|c|}{ Not stated } & \multicolumn{2}{|c|}{ Not stated } & No difference & No difference & Rosner $[10,11]$ \\
\hline $\mathrm{AML}$ & 43 & $\mathbf{M}$ & \multicolumn{2}{|c|}{ Not stated } & $8.0^{7}$ & 3.9 & \multicolumn{2}{|c|}{ tyon } & & & \\
\hline CLL & 38 & M & \multicolumn{2}{|c|}{ No difference } & \multicolumn{2}{|c|}{ No difference } & \multicolumn{2}{|c|}{ No difference } & & & \\
\hline CML & 13 & $\mathbf{M}$ & \multicolumn{2}{|c|}{ Increased } & Not & ated & Not s & ated & & & \\
\hline ALL & 14 & $\mathrm{~F}$ & Nots & ated & Nots & ated & Nots & ated & & & \\
\hline AML & 24 & $\mathrm{~F}$ & Nots & ated & Not s & ted & Not $\mathrm{s}$ & ated & & & \\
\hline CLL & 22 & $\mathrm{~F}$ & Nots & ated & Nots & ated & Incre & sed & & & \\
\hline $\mathrm{CML}$ & 18 & $\mathrm{~F}$ & Incre & $\operatorname{sed}^{8}$ & Nots & ated & Not $\mathrm{s}$ & ated & & & \\
\hline All types & 175 & $M \& F$ & $32.8^{9}$ & 32.8 & 5.7 & 3.5 & 4.3 & 4.2 & Not stated & Not stated & Aleksandrowic $\%$ et al. [1] \\
\hline Acute & 56 & $M \& F$ & Not $s$ & ted & Not $s$ & ted & Nots & ated & No difference & No difference & Nora et al. [7] \\
\hline
\end{tabular}

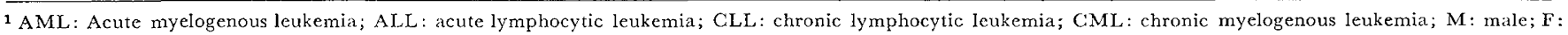
female.

2 The frequency of ulnar loops is not shown: ulnar loops represent the remainder needed to reach $100 \%$.

3 Fathers.

4 Brothers.

5 Mothers.

${ }^{6}$ Sisters.

7 Right hands only.

${ }^{8}$ Left hands only.

${ }^{9}$ Female patients had excess whorls.

In 1966, Aleksandrowicz et al. [1] and in 1969, Menser and Purvis-Smith [5] reported that patients with leukemia had distinctive dermatoglyphic features. These studies were criticized because a small series of patients with various types of leukemia were presented jointly and that the data was not separated by sex.
The flurry of publications following the initial studies gave conflicting results. We have summarized most of the previous studies and our own data in Table $\mathrm{V}$. The inconsistencies of some results listed in Table $\mathrm{V}$ stem probably in part, from the difficulty of collecting large groups of patients suffering from a single type of 
leukemia and the unavailability of control subjects who have similar ethnic and age characteristics. Taking this into consideration, our study group consists exclusively of patients with acute lymphocytic leukemia. As ethnic and geographic origins of our patients were heterogeneous, we utilized two types of control groups, first degree relatives and unrelated normal individuals.

Our study and several earlier studies summarized in Table $V$ reveal that male patients with leukemia tend to have a higher frequency of digital whorls. When males with leukemia were compared with their own normal male sibs, the distinctness of males with leukemia remained obvious (Fig. 2). Similar results were reported by Verbov [14], who found that in acute leukemia only the males had an increase in fingertip whorl patterns (Table V). Higher whorl fingertip patterns were also found by Menser et al. [6], Rosner [10, 11], and Zahalkova et al. [18] (Table V). Why male patients with leukemia show differences in their digital patterns and female patients with leukemia do not is not clear at this time. However, we noted a similar sex effect in our study of birth weight distribution in the same sibships as those presented here. The birth weights of the patients with leukemia were significantly greater than those of their normal sibs and the association of acute lymphocytic leukemia to greater birth weight was stronger in male than in female patients [15].

Our study of palmar flexion creases of patients with leukemia concurs with several earlier reports which concern the greater frequency of Sydney creases in leukemia (Table V). In addition, our results indicate that Sydney creases are more frequent in the sibs of patients with leukemia as well. The patient-sib agreement suggests that Sydney creases represent a characteristic of the sibship of which the patient with leukemia is a member, rather than being distinctive of patients with leukemia only. Our study does not indicate major differences in the frequency of simian creases in patients having leukemia.

Some of the results of dermatoglyphic studies on leukemia summarized in Table $V$ do not support our findings, but consideration has to be given to the fact that many reports were preliminary communications, analyzed in a variety of ways, and concerned with a few patients suffering from a variety of forms of leukemia. For instance, in our previous study, the reported frequency of Sydney creases was determined by combining the complete and aberrant types [16]. Because the definition of a Sydney crease as aberrant is some- what subjective, in this study the aberrant types were treated separately. However, the exclusion of aberrant Sydney creases from consideration does not alter appreciably the conclusions concerning the greater frequency of Sydney creases in leukemia.

When the previous studies and our own research are taken into account, it appears that patients with acute lymphocytic leukemia have an excess of Sydney palmar flexion creases and that male patients have an excess of digital whorl patterns. Even if this evidence is considered inconclusive, an association of leukemia to dermatoglyphic and birth weight characteristics is of sufficient importance to warrant its use as an a priori hypothesis for future studies. If confirmed, this could lead to a better understanding of the prenatal characteristics of those who develop leukemia and further the knowledge of risk factors for this disorder.

\section{Summary}

The dermatoglyphic features of 76 patients with acute lymphocytic leukemia were compared with those of their sibs, parents, and normal control subjects. Male patients with leukemia have a higher frequency of digital whorls than male sibs or fathers. Leukemia patients and their sibs have more Sydney palmar flexion creases than their parents or normal control subjects. The association of leukemia to distinctive dermatoglyphic features may represent another prenatal characteristic that may contribute to the understanding of risk factors for leukemia.

\section{References and Notes}

1. Areksandrowicz, J., Schrffrr, \%, and Debski, T.: Dermatoglyphics in leukaemia. Lancet, ii: 1364 (1966).

2. Brrka, I.., McCrlrf, P. D., Sontly, M. J., AND Thompson, M. W.: Dermatoglyphics in chillhood leukemia. Can. Med. Ass. J., 105: 476 (1971).

3. Carvalho, R. I.: Minor congenital abnormalities, dermatoglyphics and childhood leukemia. Rev. Brasil. Pesquisas Med. Biol., 2: 51 (1969).

4. Hor.r, S. B.: The Genetics of Dermal Ridges, P. 40. (Charles C Thomas, Publisher, Springfield, Ill., 1968).

o. Menser, M. A., ani) Purvis-Smith, S. G.: Dexmatoglyphic defects in children with leukacmia. Lancet, $i: 1076$ (1969).

6. Menser, M. A., and Purves-Smity, S. G.: Dermatoglyphics in leukacmia. Lancet, $i: 956$ (1972).

7. Nora, A. H., NorA, J. J., ANI Fernbach, D. J.: Dermatoglyphics and leukacmia. Lancet, $i i: 905$ (1969).

8. Pi.ATo, C. C.: Polymorphism of the $C$ line of palmax dermatoglyphics with a new classification of the $C$ line terminations. Amer. J. Phys. Anthropol., 33: 413 (1970).

9. Plato, C. C., Cereghino, J. J., ANd Steinberg, F. S.: Palmat dermatoglyphics of Down's syndrome: Revisited. Pediat. Res, 7: $111(1973)$. 
10. Rosner, F.: Dermatoglyphics of leukaemic children. Lancet, ii: 272 (1969).

11. Rosner, F.: Dermatoglyphics in leukacmia. Lancet, $i i: 882$ (1970).

12. Stowens, D., and Sammon, J. A.: Dermatoglyphics and leukaemia. Lancet, $i: 846$ (1970).

13. Verbov, J. L.: Dermatoglyphics and leukaemia. Lancet, ii: 323 (1969).

14. Verbov, J. L.: Dermatoglyphs in Ieukaemia. J. Med. Genet., 7 : $125(1970)$.

15. Wertelecki, W., AND MANtel, N.: Increased birth weight in leukemia. Pediat. Res., 7: I32 (1973).

16. Wertelecki, W., Plato, C. C., and Fraumeni, J. F.: Dermatoglyphics in leukaemia. Lancet, ii: 806 (1969).
17. Wittrwer, B., and Gressmann, H. G.: Dermatoglyphics and leukaemia. Lancet, $i: 425$ (1970).

18. Zahálková, M., AND BĚLušA, M.: Dermatoglyphics in children with leukaemia. Lancet, $i$ : 1236 (1970).

19. We thank Dr. E. S. Henderson for permission to study these patients, Dr. R. W. Miller for his support, and Mrs. L. Whitfield for secretarial assistance.

20. This work has been supported in part by a National Science Foundation grant to the Medical University of South Carolina.

21. Requests for reprints should be addressed to: W. WERTELECKI, M.D., Medical Genetics, Department of Pathology and Pediatrics, Medical University of South Carolina, Charleston, S. C. 29401 (USA).

22. Accepted for publication February 28, 1973. 